\title{
The Control Strategy of Hybrid Energy Storage System Charging Kai $\mathrm{LI}^{1, \mathrm{a}^{*}}$, Xiang-Qun CHEN ${ }^{1}$, Jing-Bai $\mathrm{LI}^{1}$, He-Qing ZENG ${ }^{1}$, Lei YANG ${ }^{2}$ \\ ${ }^{1}$ State Grid Hunan Electric Power Company Metrology Center, Changsha \\ ${ }^{2}$ Beijing Puri High-voltage Transmission Technology Co., Ltd of State Grid, Beijing \\ a18338567@qq.com \\ ${ }^{*}$ Corresponding author
}

\begin{abstract}
Keywords: control Strategy, hybrid energy storage system, power quality, simulation and experimental.
\end{abstract}

\begin{abstract}
The Electric Car Era is coming. According to the battery charge of car, the optimized control Strategy applied to DC-DC converters of electric vehicles, it is to gain further loss reduction and improve the life of an electric car battery. The hybrid energy storage system adopts the combination of current controller and peak current controller, which improve filter performance and optimize the power quality of the hybrid energy storage system. The hybrid energy storage systems consist of battery and ultracapacitor, Finally, the simulation and experimental results verifies that the control Strategy has the ability of good performances.
\end{abstract}

\section{Introduction}

In order to make electric vehicles the same as fuel vehicles, they need have a fast transient acceleration energy, long-distance endurance and light-weight multiple storage devices. The introduction of power prediction feedback link in a control system can speed up the combination process between the energy storage system and the wind power system [1]. A hybrid energy storage system uses fuzzy power control theory to distribute power, with the output power of renewable energy fluctuated. When the super capacitor is fully charged, the power is provided by the storage system independently, which will reduce charge and discharge times of the battery [2]. As an optimal control method based on smoothing time and limited power, the battery maximum power and the climbing maximum power will be take into consideration In the energy storage system [3].

The integrated magnetic structure of DC-DC converter, as the connection of energy storage system and the grid and the essential part of the DC motor, which is more simpler and efficient, can significantly reduce the volume and weight of the converter [4-10]. In this paper, the proposed DCDC converter gives the specific topology and specific operating modes, as well as the battery and the super capacitor. Finally, simulation and experimental analysis shows that the performance of the hybrid energy storage system is in line with the theoretical analysis.

\section{Hybrid energy storage system}

Fig. 1. is a proposed hybrid energy storage system composed of DC/DC converters, super capacitors and a battery pack. DC/DC converters consist of four IGBT switches T1-T4 and their corresponding diodes (added battery) tube D1-D4, an integrated magnetic structure-selfinductance $\mathrm{L}_{1}, \mathrm{~L}_{2}$ and mutual-inductance $\mathrm{M}$, which share a core inductor. The battery pack provides power for the smooth DC motor, which is a major energy electric vehicle. The super capacitor is used to deal with the instantaneous state of peak power supply. The power management system according to the load demand determines the electrical energy flow. 


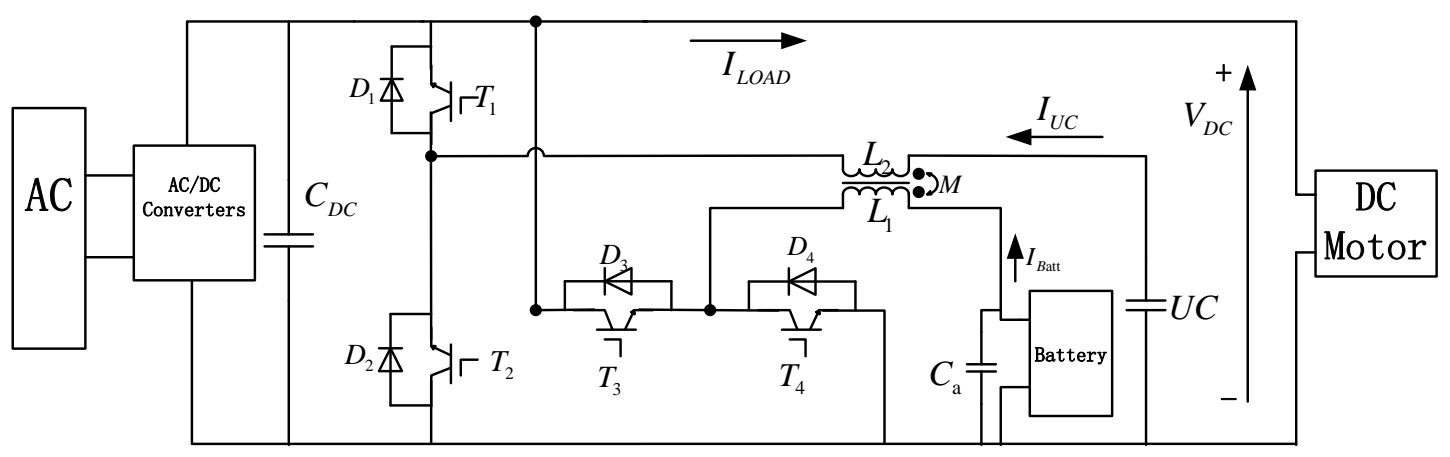

Fig.1 Topology of the hybrid energy storage system

\section{Control Strategy}

super capacitor controller. Selection cascade voltage and current controller as a super capacitor controller because when the battery provide a stable load voltage, super capacitor can maintain voltage of the DC side. This ensures that during braking, due to a significant increase in the DC side voltage, super capacitor can respond more rapidly, recovery of braking energy. Figure 2 is a control block diagram of the super cascade voltage capacitor and current controller.

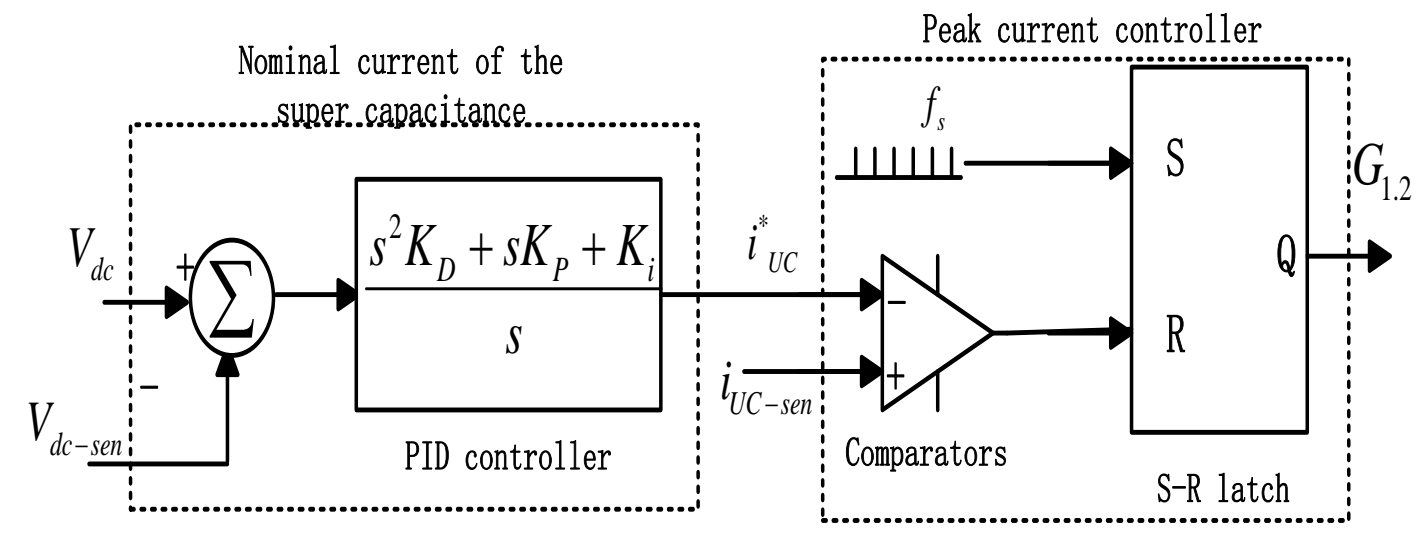

Fig.2 Block diagram of the Ultra-capacitor voltage and current controller

In boost mode the duty cycle of the inductor current's transfer function can be expressed as:

$$
\frac{I_{L 2(s)}}{D_{(s)}}=\frac{V_{d c} R_{\text {Load }} C_{d c} s+2 V_{d c}}{R_{\text {Load }} L_{2} C_{d c} s^{2}+L_{2} s+R_{\text {Load }}(1-D)^{2}}
$$

$I_{L 2(s)}$ is the reference current $L_{2}, V_{d c}$ is a DC motor voltage, $C_{d c}$ is a DC motor side capacitor, D is the duty cycle. In the frequency range, the relationship between the inductor current and the DC -side voltage represented by the following formula ;

$$
\frac{V_{d c}(s)}{I_{L 2}(s)}=\frac{-L_{2} s+R_{\text {Load }}(1-D)^{2}}{R_{\text {Load }} C_{d c}(1-D) s+2(1-D)}
$$

battery controller. Current control of the battery pack aims to ensure smooth supply of the DC motor current, therefore, the output current (corresponding to the battery control )of the battery pack through a second-order cut-off frequency of $50 \mathrm{~Hz}$ Bessel low-pass filter. This ensures that there is no high output current ripple or transient big change. And because the output current of the buck converter generally contains higher output current ripple, therefore, the battery pack during normal operation through the transmission of electrical energy boost converter. Only in the battery charging, through the buck converter power transmission. Therefore, the output current battery containing ripple ratio can be greatly reduced.

Assuming lossless converter, the DC motor current is equal to the battery current and the battery current and the DC current ratio may be expressed as: 


$$
V_{\text {load }} \times I_{\text {load }}=V_{\text {batt }} \times I_{\text {batt }} ; I_{\text {batt }}=\frac{V_{\text {load }} \times I_{\text {load }}}{V_{\text {batt }}}
$$

The reference current of the battery pack is expressed as:

$$
I_{\text {batt }}^{*}=\frac{V_{\text {load }} \times I_{\text {load }}}{V_{\text {batt }}} G_{L P}(s)
$$

$G_{L P}(s)$ as transfer function for Bessel low-pass filter can be expressed as:

$$
\begin{aligned}
G_{L P}(s)= & \frac{\theta_{n}(0)}{\theta_{n}\left(s / \omega_{0}\right)}= \\
& \frac{b(1) s^{n}+b(2) s^{n-1}+\ldots+b(n+1)}{s^{n}+a(2) s^{n-1}+\ldots+a(n+1)}
\end{aligned}
$$

$\theta_{n}(s)$ is the inverse Bessel polynomials, $\omega_{0}$ is a desired cutoff frequency obtained, $a(n)$ and $b(n)$ are coefficients of the polynomial Bezier, for the second-order Bessel filter, the transfer function of the filter can be expressed as:

$$
G_{L P}(s)=\frac{b}{s^{2}+a s+b}
$$

Bessel filter is a linear filter, which has the largest flat group delay or linear phase response, so after a Bessel filter can fully retain filtered the waveform after filtering, and maintain the basic stability group delay in the whole process of filter. Once the battery output reference current, the converter is controlled by the peak current controller, figure 3 is a specific control block diag.

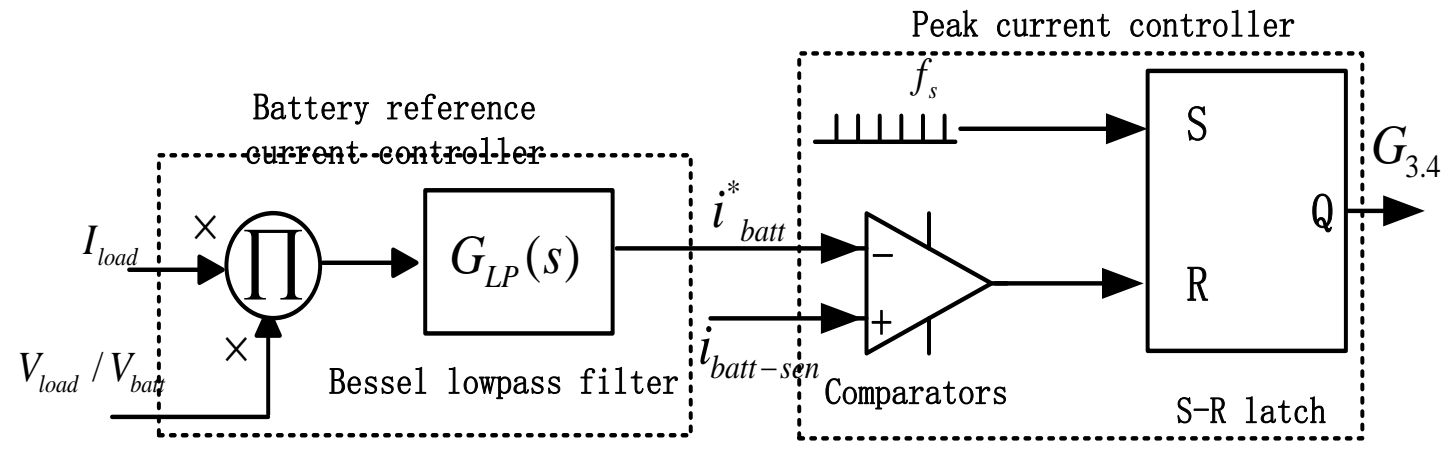

Fig.3 The block diagram of battery control

\section{Control strategy in an mode.}

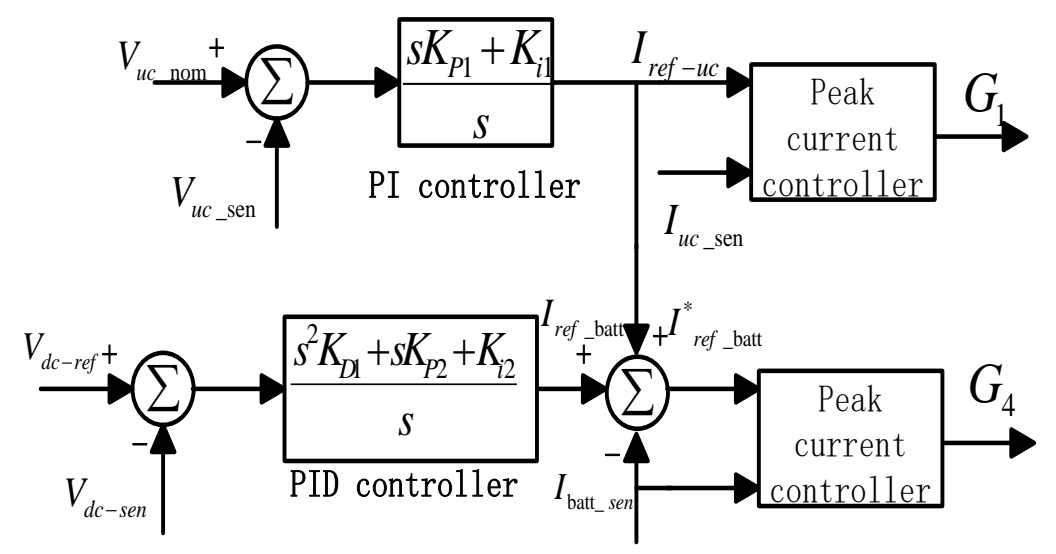

Fig.4 Block diagram of the control system while operating in Mode

Working mode includes a battery pack providing power for the DC motor and super capacitors to obtain power from the DC side. Under normal operating conditions, provide stable power by the 
battery. when the super capacitor is lower than the limit value by controlling the converter switches, super capacitor charging obtained power from the DC side. Figure 4 is a control block diagram working in the operation mode $5, V_{u c_{-} n o m}$ is the rated voltage $U C, V_{u c_{-} \text {sen }}$ is the actual voltage $U C, G_{1}$ and $G_{4}$ as switch off signal.

\section{Simulation and Experimental Analysis}

Built a small-scale experiment with analog circuits, adopt bootstrap PC2500 super capacitor, TMS320F2812 DSP as feedback and control systems, inductors $L_{1}, L_{2}$, the respective value of M is $2 m H, 50 m H, 50 \mu H$,and the actual value is shown in Table 1.

Tab.4 Experimental equipment and circuit parameters

\begin{tabular}{|c|c|}
\hline \multicolumn{2}{|c|}{ Experimental data } \\
\hline DC side voltage & $V_{d c}=20 \mathrm{~V}$ \\
\hline Battery & $\begin{array}{l}V_{\text {batt }}=12 \mathrm{~V} \\
\text { the initial charge state } 80 \% \\
\text { lead - acid battery }\end{array}$ \\
\hline Super Capacitor & $\begin{array}{l}6 \text { Maxwell Boostcap } P C 2500 \text { Series connection } \\
450 F \text {, the initial state of charge } 12 \mathrm{~V}\end{array}$ \\
\hline Switching frequency & $f_{s}=20 \mathrm{kHz}$ \\
\hline Sampling time & $T_{\mathrm{sc}}=20 \mu \mathrm{s}$ \\
\hline DSP model & $T I-T M S 320 F 2812$ \\
\hline$L_{1}, L_{2}, M$ & $1.938 \mathrm{~m} H, \quad 54.5687 \mu H, \quad 52.7866 \mu H$ \\
\hline Switch model & HGTG30N60A4D IGBT \\
\hline Voltage sensor & $L V 20-P$ \\
\hline Current sensor & $L A 100-P$ \\
\hline
\end{tabular}

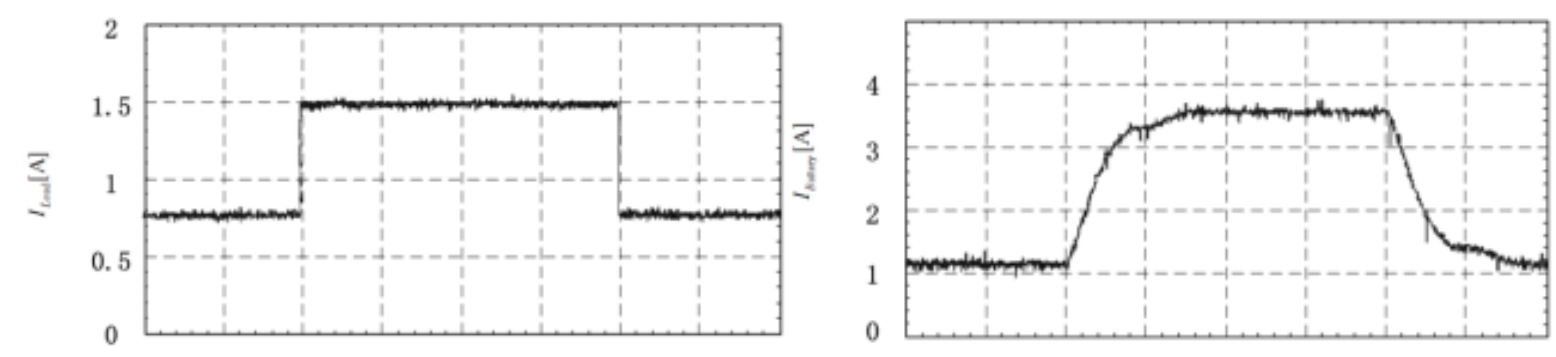

Fig.5 Experimental results under a load step change: load, battery pack, and ultracapacitor currents
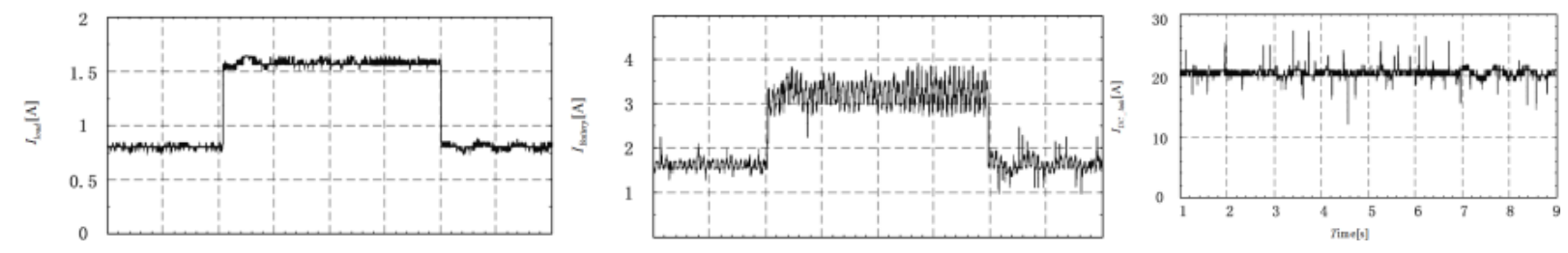

Fig.6 Load, battery pack, and ultracapacitor currents under a load step change only with the battery

Figure 5 shows the excellent handling capacity of hybrid energy storage system in response to the acceleration and braking condition. As we can see from the figure, when $t=3$, the load steps up, battery current do not respond immediately. However, by controlling the slow climb, the super capacitor soon discharges with high-current, supplemental power required on the load side. At the same time, DC voltage stabilized at $20 \mathrm{~V}$, the overall volatility is less than $5 \%$. When $\mathrm{t}=7$, the load steps down, ultracapacitor recovers by using energy of the brake. As we can see from the figure , the value of the super capacitor current is negative. Only when the battery pack is a single storage device can current fluctuates and higher ripple occurs(Figure 6).If current battery pack surges and 
sags, it is not conducive to a long-term use of the battery pack. Compared with Figure 5 and Figure 6 , the use of the battery pack and the ultracapacitor hybrid energy storage system can cope with vehicle acceleration and the braking better. It is also quite a good idea to use the magnetic integrated structure to filter the ripple effect.

\section{Conclusions}

Compared to traditional hybrid energy storage system, this system has significantly reduced its volume, weight and the influence caused by the ripples of the DC motor. Super capacitor controller combination cascade voltage with current control strategy, battery combination peak current controller with reference current controller, constitute the simple and reliable control system, which can maintain the DC motor side voltage stability and improve the control stability.

\section{Acknowledgments}

This work was supported by STATE GRID Corporation of China research project-Research on field test and operation evaluation technology of EV charging equipment.

\section{References}

[1] LIANG Liang, LI Jianlin, HUI Dong. Optimization configuration for capacity of energy storage system in large-scale wind farm[J]. High Voltage Engineering, 2011, 37(4): 930-935

[2] DING Ming, LIN Gende, CHEN Zinian, et al. A control strategy for hybrid energy storage systems[J]. Proceedings of the CSEE, 2012, 32(7): 1-6.

[3] XIE Junwen, LU Jiming, MAO Chengxiong, et al. Optimal control of battery energy storage system based on variable smoothing time constant[J]. Automation of Electric Power Systems, 2013, 37(1): 96-102.

[4] CHEN Qian-hong,Ruan Xin-bo, Yan Yang-guang. The application of the magnetic-integration techniques in switching power supply[J].Transactions of China Electrotechnical Society, 2004, 19(3): $1-7$.

[5] LIU Xue-chao, ZHANG Bo, QIU Dong-yuan. Modeling of multiphase parallel magnetic integrated circuit voltage regulator module[J]. Chinese Society for Electrical Engineering, 2006, 16(19):145-151.

[6] QIAO Lei, LIU Yong-qiang. Integrated magnetic technology and its application in power electronic[J]. Pr- oceedings of the CSU - EPSA, 2005, 17(3): 34-38.

[7] WANG Hua-feng, CHEN Ming, , et al.Application of shunt active power filter with integrated magnetics[J]. Electrical Applications,2006, 25(12): 80-84.

[8] CAI Xuan-san, GONG Shao-wen. High frequency power electronics[M].Beijing: Science Press, 1993:100-156.

[9] O. Onar and A. Khaligh. Dynamic modeling and control of a cascaded active battery/ultracapacitor based vehicular power system[J]. Proc.Veh Power Propulsion Conf. (VPPC), Harbin, $2008,: 1-4$.

[10] YANG Yu-gang. Magnetic technology of modern power electronics[M]. Beijing: Science Press, 2003: 54-79. 